\title{
Dental concerns of children with cleft lip and palate- a review
}

\begin{abstract}
The incidence of cleft lip and palate varies from 0.5 to 3.63 per 1000 live births and factors responsible for development of cleft lip and palate are genetic, environmental and geno-environmental interactions. Cleft lip may be associated with syndromes like Down's, Vander Woude's and Pirre Robin syndrome etc. Palatal repair may inhibit the growth of maxilla due to scar contracture. Numerous tooth defects are commonly seen in cleft lip and palate cases. Babies with cleft palate are unable to suck mother's milk because intraoral negative pressure is not possible. Rule of ten is followed as a guide for timing of lip and anterior palate repair. Single stage repair at the age of one and half years produces normal speech at $50-70 \%$ of cases. Children with a cleft of palate are prone to upper respiratory tract infections leads to a high incidence of middle ear problems and resultant defects in hearing. If orthographic surgery is done to correct the underlying skeletal imbalance, preoperative orthodontic treatment is needed to achieve proper alignment of teeth. This article discuss about etiology, clinical features, and management of cleft lip and palate.
\end{abstract}

Volume 8 Issue 4 - 2018

SVSG Nirmala,' Degala Saikrishna ${ }^{2}$

'Department of Paedodontics \& Preventive Dentistry, Narayana Dental College \& Hospital, India

${ }^{2}$ Department of Oral and Maxillofacial Surgery, JSS Dental College and Hospital, Mysore, Karnataka, India

Correspondence: SVSG Nirmala, Professor, Department of Paedodontics \& Preventive Dentistry Narayana Dental College \& Hospital, Nellore, Andhra Pradesh-524003, India, Email nimskrishna2007@gmail.com

Received: February 12, 2018 | Published: July 19, 2018

\section{Introduction}

These are the most severe of congenital anomalies which affect the mouth and related structures. There are one of the most common congenital defects and occur about once in 1000 births. ${ }^{1}$ There is a family history in only about one third of cases. Clefts of the palate only are more common in girls while clefts of the lip, with or without palatal involvement, are more common in boys. It is interesting to know that the left side is more often than the right. ${ }^{2}$ The exact cause of clefting is unknown in most cases. For most cleft conditions, no single factor can be identified as the cause. However, it is important to distinguish between isolated clefts (in which the patient has no other related health problems) and clefts associated with other birth disorders or syndromes. ${ }^{3,4}$ In the absence of the family history the occurrence of a congenital abnormality may be due to the action of mutation or some chance occurrence during the pregnancy. The lips and palate develop during the 5-8 weeks of intrauterine life and any factor disrupting the heir formation must exert its influence during this relatively short period. In this respect it is difficult to offer positive views on factors related to maternal health during the pregnancy. it is accepted that German measles and x-ray examination during early pregnancy may produce congenital abnormalities and are to be avoided. The teratogenic action of certain drugs, particularly thalidomide is well known. Infarct the expectant mother is well advised to avoid all necessary drugs taking during the early stages of pregnancy. ${ }^{5-7}$ (Table 1-3) A useful classification of clefts is that of Kernahan and stark which is bases on an embryological considerations of the tissues involved there are essentially three main groups. ${ }^{7,8}$

\section{Classification ${ }^{7,8}$}

(Tables 4-6)

Group I-comprises those which involve the lip, alveolus and anterior part of the palate as far as palatal foramen these are clefts of primary palate

Group II-represents those clefts of soft palate which may extent forward to involve the hard palate as far as palatal foramen, these are clefts of secondary palate.
Group III-comprises clefts of both primary and secondary palates these may be unilateral or bilateral.

Group IV-Rare facial clefts

Children with a cleft of palate are prone to upper respiratory tract infections, and as a result there is a high incidence of middle ear problems and resultant defects in hearing.

Table I Incidence of Cleft lip and palate in different races. ${ }^{6}$

\begin{tabular}{ll}
\hline Geographic race & Incidence per 1000 live births \\
\hline Negroes & 0.5 \\
Caucasians & $\mathrm{I}$ \\
Japanese & 2.34 \\
Americans & 2.91 \\
Indians & 1.27 \\
\hline
\end{tabular}

Table 2 Incidence of different types of Cleft. ${ }^{6}$

\begin{tabular}{ll}
\hline Type of cleft & Incidence \\
\hline Cleft lip only & $25 \%$ \\
Cleft palate only & $25 \%$ \\
Cleft Lip and Palate & $50 \%$ \\
\hline
\end{tabular}

Table 3 Prevalence of different types of Cleft in India. ${ }^{6}$

\begin{tabular}{ll}
\hline Place & Type of cleft with percentage \\
\hline & CLP CP CL \\
Dharwad & $44.3 \quad 12.842 .9$ \\
Delhi & 6818 I 4 \\
Chennai & $84.7 \quad 1.913 .3$ \\
\hline
\end{tabular}


Table 4 Morphological classification.

\begin{tabular}{|c|c|}
\hline Group I & Cleft of the soft palate only. \\
\hline Group II & Cleft of the hard and soft palate till the incisive foramen. \\
\hline Group III & $\begin{array}{l}\text { Complete unilateral Cleft of the soft palate, hard palate, } \\
\text { the alveolar ridge and the lip on one side. }\end{array}$ \\
\hline Group IV & $\begin{array}{l}\text { Complete unilateral Cleft of the soft palate, hard palate, } \\
\text { the alveolar ridge and the lip on both side }\end{array}$ \\
\hline
\end{tabular}

Table 5 Embryological classification. ${ }^{9}$

\begin{tabular}{lll}
\hline Group I & Unilateral bilateral & $\begin{array}{l}\text { Total , Subtotal } \\
\text { Total, Subtotal }\end{array}$ \\
\hline $\begin{array}{l}\text {-Cleft of the primary palate } \\
\text { only }\end{array}$ & \\
Group II & \\
-Cleft of the Secondary palate only & \\
Group III & Unilateral & Total, Subtotal \\
--Cleft of the both primary & Median & Total, Subtotal \\
and secondary palate & Bilateral & Total, Subtotal \\
\hline
\end{tabular}

Table 6 Spina classification. ${ }^{9}$

\begin{tabular}{ll}
\hline Group I & Unilateral \\
\hline Pre incisive foramen cleft & Bilateral \\
& Median (Cleft of the lip with or without \\
& an Alveolar cleft). \\
& It can be Total, partial.
\end{tabular}

Group II

Transnincisive foraman clefts (Cleft of the lip, alveolus and palate)

Unilateral

Bilateral

Group III

Post incisive foramen cleft

Total

Partial

Group IV

Rare facial clefts

Clefts of the lip and palate give rise to problems related to actual structures involved in a cleft .in general, clefts of the lip give rise to aesthetic problem, clefts of alveolus give rise to dental problems and clefts of palate give rise to speech problems. These structures are of course closely inter related and thus the problems not always isolated, for example the features related to the cleft of the alveolus may also contribute to a speech defect. The cleft of the alveolus rarely occurs in the absence of a clef of the lip or palate. all clefts of the lip and palate present a surgical challenge.10 The vast majority, well over $90 \%$, of cleft lip and palate children develop normal speech, a minority requiring the help of a speech therapist many of them appear to present speech problems similar to those of other normal children and it would seem that as such hey are not related to actual cleft. On occasions special speech problems arise which benefits from close liaison between speech therapist and dental surgeon. ${ }^{11}$ A syndrome is a set of physical, developmental, and sometimes behavioral traits that occur together. Clefts have been identified as one feature in over 300 syndromes, most of which are quite rare. Syndromes account for roughly $15 \%$ of the total number of cases of cleft lip and/or palate. ${ }^{12}$

\begin{tabular}{|c|c|c|}
\hline $\begin{array}{l}\text { S } \\
\text { No }\end{array}$ & $\begin{array}{l}\text { Syndromes associate } \\
\text { with Cleft Lip }\end{array}$ & Features \\
\hline I & \multicolumn{2}{|c|}{ Down”s syndrome (Trisomy 2I) } \\
\hline 2 & Wardenburg"s syndrome & $\begin{array}{l}\text { Abnormalities of pigmentation of } \\
\text { hair, skin, irism deafness }\end{array}$ \\
\hline 3 & $\begin{array}{l}\text { Vander Woude's } \\
\text { syndrome }\end{array}$ & Lip pits \\
\hline 4 & $\begin{array}{l}\text { Orofacial digital } \\
\text { syndrome: }\end{array}$ & $\begin{array}{l}\text { Median cleft lip associated with } \\
\text { post axial hexadactyly and bilateral } \\
\text { accessory toes }\end{array}$ \\
\hline \multirow[t]{2}{*}{5} & $\begin{array}{l}\text { Treacher Collins } \\
\text { Syndrome }\end{array}$ & Hypoplastic zygoma, micrognathia, \\
\hline & & External and midle ear defects \\
\hline 6 & Pierre Robin sysdrome & $\begin{array}{l}\text { Micrognathia, glossoptosis with } \\
\text { respiratory obstruction }\end{array}$ \\
\hline 7 & Klippel-Fiel syndrome & $\begin{array}{l}\text { Short neck with an abnormal or } \\
\text { missing cervical vertebra }\end{array}$ \\
\hline
\end{tabular}

\section{Genetic factors (Monogenic)}

Cleft lip associated with cleft palate is more common in males. Cleft palate alone is more common in female. This shows vague influence of heredity over occurrence of clefts. In about one-fifth to two-fifth of these patients, a positive family history can be elicited. Vander Woude's syndrome where lip pits are associated with cleft lip and palate gives rise to Mendelian pattern of autosomal recessive inheritance. In rare clefts the hereditary factor seems to be very unusual.

\section{Gene (Polygenic) environment interactions}

Many cleft lip and palate cases show a slight familial tendency but do not give rise to the Mendelian patterns of inheritance. In these cases, the interaction between multiple genes with small defects and environmental factors results in the defect. There is increasing evidence that most clefts in human beings appear due to multi factorial causes, i.e., due to combined effect of genetic influence and various environmental factors. ${ }^{10,13}$

\section{Behavioral}

Children may have hyper nasal speech which is difficult to understand as a result of velopharyngeal insufficiency. Many young children with clefts will exhibit shy, nervous, or uncooperative behavior. This may have to do with previous hospitalization or frequent hospital visits. Bone support for these teeth is generally poor. Teeth that are present may be malformed and prone to caries. Parents appreciate education about teeth present or missing, surrounding a cleft. Simple explanations about the variability of teeth at the cleft site may allay concerns. Panoramic and/or Occlusal radiographs are indicated to monitor development. The majority of children with a cleft palate will require orthodontics. Orthodontic treatment may be required in the primary, mixed, and permanent dentition. Facilitate contact with an orthodontic provider if child has not been evaluated..$^{14,15}$ 


\section{Outline of surgical treatment}

\section{Naso Alveolar Moulding (NAM)}

The management of cleft patients has evolved dramatically in recent years. Outcome is improving because of better surgical techniques, timing, and incorporation of procedures like pre surgical orthopedics. Pre surgical infant orthopedics was first introduced by McNeil 1 in 1950. Since then, techniques are changing and so are the results. Active molding and repositioning of the nasal cartilages take advantage of the plasticity of cartilage in the newborn infant. ${ }^{16,17}$ In the last decade, it has been shown that correction of nasal deformity by stretching of the nasal mucosal lining, and achievement of nonsurgical columella elongation can be combined with molding of the alveolar process in cleft patients. ${ }^{18,19}$ The impression was obtained with the infant fully awake, in prone position without anesthesia. Before impressions, child was kept nil orally for about 2 hours. Impressions were taken on dental chair with child in the lap of his or her parents. Impression should be taken very carefully and is always done after insuring the availability of anesthesia team. First, the impression tray was checked in the mouth of patient. After selection of a proper size tray, alginate paste was made, loaded in the tray, and inserted in the mouth. Soon after this, alginate paste was applied over the plate by hand up to root of the nose. Child'slower jaw was pulled down, and precautions were taken to avoid falling of impression material into oral cavity. After some time (15-20s), this nose, lip, and alveolus negative impression was removed in a single piece. Oral and nasal cavities were inspected for any remaining particles. After impression, a dental stone cast was made by filling it with paste of dental stone material. It was allowed to fix. Dental stone model was made for purpose of measurements and fabrication of appliance. These dental stone casts were labeled with patient's name, age/sex, and date. A conventional molding plate was fabricated on the maxillary cast using clear acrylic resin with a nasal stent wire passed from it going superiorly toward nose. The tip of wire was covered with hard and then soft acrylic. At the active tip of nasal stent, the acrylic was covered with a thin layer of soft denture lining material to insure that tissue irritation does not occur when pressure is applied for nasoalveolar molding.

After the nasoalveolar molding plate was ready and check for any rough areas.Plate was handed over to parents, and they were explained about maintaining oral hygiene, cleaning, insertion, and removal of plate. Patients were called at weekly intervals to gradually change the direction of nasal wire. At every visit, local area was examined for any ulceration or pressure points. Measurements of different nasal parameters and alveolus were taken on prepared dental stone model as well as on patients directly with the help of thread and artery forceps, and were recorded. It was done for the purpose of accuracy. Measurements on patients were matched with measurements on dental models, and they were found to be almost similar. ${ }^{20,21}$ It is desirable to provide continuity of soft tissues so that various soft tissue functional units may assume their normal functions at a time as near normal as possible. Surgery to repair the lip cleft is usually carried out and above the three months of age, when the baby is about $5.5 \mathrm{~kg}$ body weight in the case of bilateral clefts, the second side is repaired some 3 months or later. The anterior part of the palate is repaired at the same time as the lip the main palatal defect is repaired between 15 and 18 months at a time when it will shortly be required for development of speech ..$^{22,23}$

\section{Oral condition}

When the alveolus is involved by the cleft the occlusion is disrupted this occurs due to action of group of related forces. firstly, the break in the continuity of the basal bone allows the collapse to occur further the tendency of the general tightness of the upper lip, following the surgical repair, tends to produce the collapse of the arch, due to firm molding action of lip in absence of a stable arch form..$^{24}$ There is often deficiency of maxillary development both in anterio posterior and also vertical direction. This increases the tendency for the development of the class III occlusion and of buccal segment open bite which is frequently seen. ${ }^{25,26}$ The lateral incisor on the same side as the cleft is often absent, or when present, may be either or mesial or distal side of cleft . it is often rotated and its root may be dilacerated. The central incisor may be hypoplastic and it is distally inclined. ${ }^{27,28}$ Children with the cleft lip or palate deformity tend to present a poor gingival state, often a high caries rate and tendency to neglect the general care of their teeth. These features appear to be closely related in that presence of good dental cares the gingival and caries problems are minimized. ${ }^{29,30}$ The emotional aspect should also be considered for the family of children with cleft lip and palate, which may give rise to negligent attitudes on oral hygiene, because of the fear to manipulate the child's oral cavity or even the attempt to avoid unpleasant procedures. ${ }^{31}$

\section{Dental treatment}

Dental caries extremely important to these children. a good dietary awareness in relation to dental caries should be encouraged from a early life, commencing with discussions between the mother and dental surgeon shortly after the birth of the child, before the surgical is commenced tooth brushing, commencing with the soft brush, as soon as first tooth is erupted, is to be encouraged as that the number of teeth is increases so do the difficulties and degree of disturbance to the child. Hence it is obviously desirable to start early. The mother sometimes deep seated concern that the accidental trauma, while brushing the teeth especially with a tearful struggling child, may result in further permanent damage to the palate. The dental surgeon should be alert to the possibility of this fear, and be ready to give reassurance that such trauma is unlikely to occur. If the domestic water supply is not fluoridated, the prescription of fluoride tablets from infancy to reduce the caries susceptibility is recommended. ${ }^{32.33}$ The presence of carious lesions leads to the need of restorative treatment, if detected on time, or tooth extraction if the extent of the lesion does not allow restoration. The atraumatic restorative technique should be indicated for initial carious lesions without risk of pulp contamination. Whenever individuals with cleft lip and palate present dental caries with risk of pulp contamination, treatment should be conventionally performed. Individuals submitted to surgery should have an excellent oral condition, removing the sources of infection that may compromise the surgery 13 Supernumerary and/or malpositioned deciduous teeth adjacent to the cleft should be maintained as long as possible, in order to preserve bone tissue that is already defective at this region. ${ }^{34,35}$ Rubber dam isolation is recommended for dental treatment whenever possible, especially in cases of unrepaired cleft palate. The rubber dam isolates the constant water flow of the high speed handpiece, dental caries or restorative material remnants, avoiding their penetration in the airway, which communicates with the oral cavity in these individuals. ${ }^{36}$

The general dental practioner can give the cleft palate patient and orthodontist very valuable help, first by training the child to aspect the dental care, and then by conserving the both primary and permanent teeth at the earliest indication. This will greatly reduce the problems that this handicapped brings and has a great psychological value in indicating the child and parent that the unsightly appearance of the teeth is low excuse for the neglect of the oral hygiene practice that 
are too often occurs. ${ }^{12}$ The tight upper lip in bilateral cases may cause difficulty in conserving the anterior maxillary teeth as well as affecting the standard of cleansing in this area. if the co operation is particularly poor, conservation under general anesthesia is considered as these children deserve all the help they can get local anesthesia produces no problems but in the events of extractions in the region of cleft, adequate radiograph to be taken to ascertain the alignment of the root if there is any degree of dilacerations, it is advisable to consult $n$ oral surgeon extraction of premaxillary teeth in case of bilateral cleft must be well supported because of the mobility of bone. ${ }^{37,38}$ The first permanent molars may be in a poor state then the almost hopeless long term prognosis of restoration these teeth are especially important if the orthodontic appliance therapy is required during mixed dentition stage. If this is so, every effort should be made to retain these teeth, if only temporarily, and it is worth while bearing in the mild that is usually desirable to avoid the very early loss, better results are obtained by removal of these teeth at 9 years of age, at a time when there is a radiographic evidence of inter radicular calcification on the mandibular second permanent molar. ${ }^{39}$

Dental anesthesia in individuals with cleft is not different for most regions in the oral cavity, except for the cleft area. At this region, the maxilla is divided in different segments by the bone defect, with individual innervations. Even though the clinical aspect is improved after surgical repair, the alveolar separation is maintained 38 this is important when teeth at this region must be anesthetized, because the malpositioning may complicate determination of the site of tooth implantation. Therefore, previous periapical radiographic examination is recommended to analyze the bone segment in which the tooth is implanted. The surgical lip repair usually causes a secondary scar fibrosis at the region, making the mucosa more resistant and consequently the puncture is more painful. The initial puncture with anesthetic infiltration should be parallel to the tooth long axis. Because of the bone defect that separates the innervations of the two cleft segments, the adjacent region must also be anesthetized to avoid pain or discomfort during treatment, using the same puncture as the nitial infiltration, yet directing the needle to this region. Anesthesia of the palatal region is always necessary. ${ }^{37,38}$

\section{Orthodontic treatment}

Much can be achieved by fairly simple orthodontic procedures to improve the occlusion of these children. Prolonged complex orthodontic treatment is to be avoided in general it is advisable to correct the lingual occlusion of upper permanent incisors shortly after the eruption. Expansion of premolar area is is best commenced when about half to three quarters of palatal surface are erupted and retention following such expansion is essential. If the lateral incisor is absent are severely rotated, a partial denture may be required . in such cases if central incisor of poor quality are severely distally inclined it may be advisable to remove this teeth as well and add it to already necessary partial denture in bilateral cases, where the premaxillary unit is mobile every efforts to be made to retain the central incisors owing to the complications nature of this floating premaxillary when the denture is requires to replace the central incisor teeth. The dental clasp should be carefully placed using dental floss ligatures to avoid the risk of aspiration. This also applies when dental clasps are placed in supernumerary, rotated or malpositioned teeth and Also, the orthodontist should be aware that the thin periodontal bone surrounding the teeth next to the alveolar cleft constitutes a limitation for tooth movement previously to alveolar bone graft procedure in patients with clefts and important aspects should be considered during orthodontic treatment before bone graft: a) Rotated teeth adjacent to the cleft should not be corrected before the bone graft surgery, because of the risk of dehiscence and fenestrations.

b) Supernumerary teeth erupted in the palatal side of clefts should be extracted at least three months before the bone graft, because the palatal mucosa may not be interrupted to cover the entire graft. $^{40-42}$

Prosthetic obturation of palatal fistulae may be necessary in some children. Referral to appropriate specialists in cases with velopharyngeal insufficiency is indicated. Clefts are often associated with middle ear problems and hearing difficulties. ${ }^{43}$

\section{Special problems}

\section{Tooth in the cleft}

A tooth is often seen lying within the cleft or in residual fold of the soft tissues following repair high in palate. Such a tooth sometimes causes local irritation to the tip of the tongue. those often concern that removal of such a tooth may allow further collapse of dental arch to occur in the presence of fistula there may be concern that removal of tooth may result in extension of fistula neither of these possible sequalae tend to occur so frequently, if indeed ever, as to cause any strong reluctance to remove such a teeth if it is source of irritation. Such teeth tend to become carious and the crown is often eventually lost. ${ }^{44,45}$

\section{Palatal fistula}

These sometimes occur, but usually present no particular problem. Very occasionally the child complains of food, particularly or milk mixtures, entering into the nasal cavity. There is seldom any complaint of large particles of food entering into the nose pre assurance is often all that is required some times in presence of nasal tone to the voice of fistula is regarded as being responsible in these cases it may be the wish of speech therapist that a simple obturator plate is fitted in order to occlude fistula if such plate fitted a careful assessment of speech must be made both with the palate in and again with it out in order to determine if indeed it is of real value. Clefts are often associated with middle ear problems and hearing difficulties ${ }^{46,47}$

\section{Lateral's' defect}

This is a characteristic speech defect in which, when the child endeavors to make the $\mathrm{S}$ sound, there is an escape of air laterally to the corner of the mouth instead of normal central flow during formation of normal S sound. any tendency of this o occur this favored by the presence of buccal segment open bite and if of course accentuated if there has been early loss of deciduous molars . It is seldom possible for the dental surgeon to help the regard to the lateral gap until the premolar teeth are erupted and orthodontic treatment, if any is contemplated, is completed. ${ }^{48-50}$

\section{Presurgical dental orthopaedics}

By the use of appliances in new born child, this is possible to greatly reduce the degree of displacement of individual segments of palate before surgery. Such treatment can be of great value, especially in the severe bilateral cases to be of greatest value indeed to be even being possible it must be commenced with in the first few days following birth. The interested dental surgeon is referred to the reading list and should be made inquiries regarding the arrangement in his locality. ${ }^{51,52}$

Protocol for dental care with specialists ${ }^{33,54}$ 


\begin{tabular}{|c|c|}
\hline Age & Treatment \\
\hline \multirow[t]{4}{*}{ At birth } & Referral \\
\hline & Feeding plate, pre surgical orthopedics \\
\hline & $\begin{array}{l}\text { Helps in surgeon in repair by stimulating palatal bone growth and preventing collapse of dental } \\
\text { arches. }\end{array}$ \\
\hline & Prepare study models and photographs \\
\hline \multirow[t]{5}{*}{ 3-5 months } & Explain parents about dental care of primary teeth. \\
\hline & Alignment of primary teeth. \\
\hline & Expansion of the palatal arch by using simple fixed appliance like a Quadhelix, W-arch etc. \\
\hline & Plasic surgeon to repair the lip. \\
\hline & ENT surgeon's first assessment \\
\hline \multirow[t]{6}{*}{12 Months } & Review y the Pediatric dentist \\
\hline & To correct the velopharygeal incompetence by giving palatal prosthetic speech appliance. \\
\hline & Possible eruption abnormalities to be explained. \\
\hline & To repair the palate by Plastic Surgeon \\
\hline & Assessment speech by Speech therapist. \\
\hline & review by ENT surgeon and Audiologist. \\
\hline \multirow[t]{4}{*}{ 2-6 Years } & Review of Facial Growth and development by Pediatric Dentist at I year interval. \\
\hline & $\begin{array}{l}\text { Pit and fissure sealants and Topical fluoride application should be done for prevention of dental } \\
\text { caries. }\end{array}$ \\
\hline & Restorations should be done if required. \\
\hline & Review by Plastic surgeon. \\
\hline \multirow[t]{4}{*}{ 6-7Years } & Mixed dentition period, review by the pediatric dentist. \\
\hline & Correction of cross bite, removal of supernumerary teeth \\
\hline & Preventive and orthodontic intervention followed by radiographic evaluation. \\
\hline & Orthodontic consultation if necessary. \\
\hline \multirow[t]{5}{*}{8 Years } & Suitability about bone grafting \\
\hline & Dental bone assessment by using lateral cephalogram, orthopantamogram, hand-wrist $\mathrm{X}$-ray etc). \\
\hline & If required, patient should be prepared for bone graft protocol. \\
\hline & Review by the speech pathologist, plastic surgeon and ENT specialist. \\
\hline & Pediatric dentist review to relieve crowding and retroclination of anterior teeth \\
\hline \multirow[t]{3}{*}{9 Years } & Combined Pedodontist and Orthodontic coalescence \\
\hline & Bone graft alveolar alveolar cleft at half to one -third root development of permanent cuspid. \\
\hline & Review by other experts if needed. \\
\hline \multirow[t]{4}{*}{$10-12$ Years } & Orthodontic consultation \\
\hline & Pediatric dentist for future treatment \\
\hline & Monitoring growth and dentition \\
\hline & Preventive measures \\
\hline \multirow[t]{4}{*}{$12-15$ Years } & Orthodontic treatment \\
\hline & Pediatric dentist review \\
\hline & Review y the Oral Surgeon and Plastic Surgeon \\
\hline & Speech pathologist to review regarding changing of the pitch of the voice in boys. \\
\hline
\end{tabular}




\section{Conclusion}

Cleft lip and palate children benefit from team approach special treatment requirements. such a team lead by the plastic surgeon should include a speech therapist and orthodontist having ready access to pediatric, ENT and dental treatment facilities. Preventive dental measures should be considered at an early age, commencing with advice to the mother shortly after birth of child. Extensive dental treatment may be requires but it should not be made more extensive or complex than is necessary to achieve a reasonable standard of dental perfection. The multidisciplinary approach towards this problem led to a steady improvement in its end-results. Now a cleft children leading a happy life in the society without many esthetic or functional deficiencies.

\section{Acknowledgements}

None.

\section{Conflict of interest}

The author declares there is no conflict of interest.

\section{References}

1. Coupland MA, Coupland AI. Seasonality, incidence and sex distribution of cleft lip and palate births in trent region. The Cleft Palate Journal. 1973-1982. 1988;25(1):33-37.

2. Abu-Hussein M. Cleft Lip and Palate -Etiological Factors. Pediatric Dentistry. 2012;49(2):149-156.

3. Melnick M. Cleft lip and palate: Etiology and pathogenesis. In Cleft lip and palate: A system of management. Edited by Kernahan DA, Rosenstein SW, Dado DV. Baltimore: Wiliams and Wilkins; 1990. 3-12 p.

4. Little J, Munger RG, Dixon MJ, et al. Cleft lip and palate. Lancet. 2009;374(9703):1773-1785.

5. Melnick M. Cleft lip and palate: Etiology and pathogenesis. In Cleft lip and palate: A system of management. Edited by Kernahan DA, Rosenstein SW, and Dado DV. Baltimore: Wiliams and Wilkins; 1990. 3-12 p.

6. Vanderas AP. Incidence of cleft lip, cleft palate and cleft lip and cleft palate among races. Cleft Palate J. 1987;24(3):216-225.

7. Niebyl JR. Drugs in pregnancy and Lactation. In Obstetrics, normal and problem pregnancies. Edited by Gabbe S, Niebyl JR, Simpson JL. New York: Churchill Livingstone; 1986.

8. Davis JS, Ritchie HP. Classification of congenital clefts of the lip and palatre. J Am Dent Assoc. 1922;79(16):1323-1327.

9. Kernaham DA, Start RB. A new classification of cleft lip and palate. Plast Reconstr Surg. 1971;22(5):435-441.

10. Precious DS, Goodday RH, Morrison AD, et al. Cleft lip and palate: a review for dentists. J Can Dent Assoc. 2001;67(11):668-673.

11. Chiu Y, Liao Y, Chen PK. Initial cleft severity and maxillary growth in patients with complete unilateral cleft lip and palate. Am J Orthod Dentofac Orthop. 2011;140(2):189-195.

12. Precious DS. Cleft lip and palate. In: Fonseca R, editor. Fonseca's oral and maxillofacial surgery. Philadelphia: W.B. Saunders Company; 2000. $27-59 \mathrm{p}$.

13. Mossey PA. The heritability of malocclusion: Part 1-Genetics, principles and terminology. Br J Orthod. 1999;26(2):103-113.

14. Pope AW, Snyder HT: Psychosocial adjustment in children and adolescents with a craniofacial anomaly: Age and sex patterns. Cleft Palate Craniofacial J. 2005;42(2):349-354.
15. Leonard BJ, Brust JD, Abrahams G, et al. Self-concept of children and adolescents with cleft lip and or cleft palate. Cleft Palate Craniofacial J. 1991;28(4):347-353.

16. Matsuo K, Hirose T. Non surgical correction of cleft lip nasal deformity in the early neonate. Ann Acad Med Singapore. 1988;17(3):358-365.

17. Matsuo K, Hirose T. Preoperative non surgical over correction of cleft lip nasal deformity. Br J Plast Surg. 1991;44(1):5-11.

18. Grayson BH, Santiago P, Brecht L, et al. Presurgical naso-alveolar molding in patients with cleft lip and palate. Cleft Palate Craniofac J. 1999;36(6):486-498.

19. Maull D, Grayson B, Cutting C, et al. Long-term effects of nasoalveolar molding on three-dimensional nasal shape in unilateral clefts. Cleft Palate Craniofac J. 1999;36(5):391-397.

20. Liao YF, Mars M. Hard palate repair timing and facial growth in cleft lip and palate: a systematic review. Cleft Palate Craniofac J. 2006;43(5):563-570.

21. Semb G, Brattström V, Mølsted K, et al. The eurocleft study: intercenter study of treatment outcome in patients with complete cleft lip and palate. Part 1: introduction and treatment experience. Cleft Palate Craniofac J. 2005;42(1):64-68.

22. Silva Filho OG, Rosa LA, Lauris RC. Influence of isolated cleft palate and palatoplasty on the face. J Appl Oral Sci. 2007;15(3):199-208.

23. Graber L, Vanarsdall R, Vig K. Orthodontics Current principles and Techniques. 5th ed. USA:Mosby; 2011. 965-989 p

24. Santiago PE, Grayson BH, Cutting CB, et al. Reduced need for alveolar bone grafting by presurgical orthopedics and primary gingivoperiosteoplasty. Cleft Palate Craniofac J. 1998;35(1):77-80.

25. Deng L, Jiang J, Li F, et al. Presurgical orthodontic treatment of complete unilateral cleft lip and palate in 100 infants. Zhongguo Xiu Fu Chong Jian Wai Ke Za Zhi. 2005;19(10):789-792.

26. Bartzela TN, Carels CEL, Bronkhorst EM, et al. Tooth agenesis patterns in bilateral cleft lip and palate. Eur J Oral Sci. 2010;118(1):47-52.

27. Ribeiro LL, Neves LT, Costa B, et al. Dental anomalies of the permanent lateral incisors and prevalence of hypodontia outside the cleft area in complete unilateral cleft lip and palate. Cleft Palate Craniofac J. 2003;40(2):172-175.

28. Maciel SP, Costa B, Gomide MR. Difference in the prevalence of enamel alterations affecting central incisors of children with complete unilateral cleft lip and palate. Cleft Palate Craniofac J. 2005;42(4):392-395.

29. Gomes AC, Neves LT, Gomide MR. Enamel defects in maxillary central incisors of infants with unilateral cleft lip. Cleft Palate Craniofac J. 2009;46(4):420-424

30. Pope AW, Snyder HT. Psychosocial adjustment in children and adolescents with a craniofacial anomaly: Age and sex patterns. Cleft Palate Craniofacial J. 2005;42(4):349-354.

31. Cheng LL, Moor SL, Ho CT. Predisposing factors to dental caries in children with cleft lip and palate: a review and strategies for early prevention. Cleft Palate Craniofac J. 2007;44(1):67-72.

32. Rivkin CJ, Keith O, Crawford PJ, et al. Dental care for the patient with a cleft lip and palate. Part 1: From birth to the mixed dentition stage. $\mathrm{Br}$ Dent J. 2000;188(2):78-83.

33. Britton KF, Welbury RR. Dental caries prevalence in children with cleft lip/palate aged between 6 months and 6 years in the West of Scotland. Eur Arch Paediatr Dent. 2010;11(5):236-241.

34. Galante JM, Costa B, Carvalho Carrara CF, et al. Prevalence of enamel hypoplasia in deciduous canines of patients with complete cleft lip and palate. Cleft Palate Craniofac J. 2005;42(6):675-678. 
35. Rivkin CJ, Keith O, Crawford PJM, et al. Dental care for the patient with a cleft lip and palate. Part 1 :from birth to the mixed dentition stage. $\mathrm{Br}$ Dent J. 2000;188(2):78-83.

36. CK Mc Neil. Orthodontic procedures in the treatment of congenital cleft palate. Dent Rec. 1950;70(5):126-132.

37. Bartzela T, Katsaros C, Shaw WC, et al. A longitudinal three-center study of dental arch relationship in patients with bilateral cleft lip and palate. Cleft Palate Craniofac J. 2010;47(2):167-174.

38. Rivkin CJ, Keith O, Crawford PJ, et al. Dental care for the patient with a cleft lip and palate. Part 2: The mixed dentition stage through to adolescence and young adulthood. Br Dent J. 2000;188(3):131-134.

39. Dalben GS, Gomide MR, Costa B, et al. Description of a clinical technique for tooth extraction in the cleft lip and palate area. Int J Paediatr Dent. 2001;11(2):143-146.

40. Silva AP, Costa B, Carvalho Carrara CF. Dental anomalies of number in the permanent dentition of patients with bilateral cleft lip: radiographic study. Cleft Palate Craniofac J. 2008;45(5):473-476.

41. Tereza GP, Carrara CF, Costa B. Tooth abnormalities of number and position in the permanent dentition of patients with complete bilateral cleft lip and palate. Cleft Palate Craniofac J. 2010;47(3):247-252.

42. Graber L, Vanarsdall R, Vig K. Orthodontics Current principles and Techniques. 5th ed. USA:Mosby; 2011. 965-989 p.

43. Carla A Evans. Orthodontic treatment for patients with clefts. Clin Plastic Surg. 2004;31(2):271-290.

44. Christos C Vlachos. Orthodontic Treatment for the Cleft Palate Patient Semin Orthod. 1996;2(3):197-204.

45. Silva Filho OG, Ramos AL, Abdo RC. The influence of unilateral cleft lip and palate on maxillary dental arch morphology. Angle Orthod.1992;62(4):283-290.
46. Carvalho Carrara CF, Oliveira Lima Je, Carrara Ce, et al. Chronology and sequence of eruption of the permanent teeth in patients with complete unilateral cleft lip and palate. Cleft Palate Craniofac J. 2004;41(6):642645.

47. Duque C, Dalben GS, Aranha AM, et al. Chronology of deciduous teeth eruption in children with cleft lip and palate. Cleft Palate Craniofac J. 2004;41(3):285-289.

48. Garib DG, Yatabe MS, Ozawa TO, et al. Alveolar bone morphology in patients with bilateral complete cleft lip and palate in the mixed dentition: cone beam computed tomography evaluation. Cleft Palate Craniofac J. 2012;49(2):208-214.

49. Kobayashi TY, Gomide MR, Carrara CF. Timing and sequence of primary tooth eruption in children with cleft lip and palate. J Appl Oral Sci. 2010;18(3):220-224.

50. Menezes R, Vieira A. Dental anomalies as part of the cleft spectrum. Cleft Palate Craniofac J. 2008;45(4):414-419.

51. Grayson BH, Cutting CB, Wood R. Preoperative columella lengthening in bilateral cleft lip and palate. Plast Reconstr Surg. 1993;92(7):1422-1423.

52. Spengler AL, Chavarria C, Teichgraeber JF, et al. Presurgical nasoalveolar molding therapy for the treatment of bilateral cleft lip and palate: a preliminary study. Cleft Palate Craniofac J. 2006;43(3):321-328.

53. Jaju R, Tate AR. The role of pediatric dentistry in multidisciplinary cleft palate teams at advanced pediatric dental residency programs. Pediatr Dent. 2009;31(3):188-192.

54. Strong SM. Adolescent dentistry: multidisciplinary treatment for the cleft lip/palate patient. Pract Proced Aesthet Dent. 2002;14(4):333-338. 